\title{
Differences in Happiness-Increasing Strategies Between and Within Affective Profiles
}

\author{
Danilo Garcia ${ }^{1-5^{*}}$, Erica Schütz ${ }^{3,6}$, Shane MacDonald ${ }^{3}$ and Trevor Archer ${ }^{2,3}$ \\ ${ }^{1}$ Blekinge Centre of Competence, Blekinge County Council, Karlskrona, Sweden \\ ${ }^{2}$ Department of Psychology, University of Gothenburg, Gothenburg, Sweden \\ ${ }^{3}$ Network for Empowerment and Well-Being, Sweden \\ ${ }^{4}$ Institute of Neuroscience and Physiology, University of Gothenburg, Gothenburg, Sweden \\ ${ }^{5}$ Department of Psychology, Lund University, Lund, Sweden \\ ${ }^{6}$ Department of Psychology, Linnaeus University, Kalmar, Sweden
}

\begin{abstract}
Background: In a recent study, Schütz and colleagues [1] used the affective profile model (i.e., the combination of peoples' experience of high/low positive/negative affect) to investigate individual differences in intentional happiness-increasing strategies. Here we used a merged larger sample, a person-centered method to create the profiles, and a recent factor validated happiness-increasing strategies scale, to replicate the original findings.

Method: The participants were 1,000 (404 males, 596 females) individuals recruited through Amazon's Mechanical Turk (MTurk) who answered to the Positive Affect Negative Affect Schedule and the Happiness-Increasing Strategies Scales. Participants were clustered in the four affective profiles using the software RopStat (http://www. ropstat.com). Analyses of variance were conducted to discern differences in how frequently the strategies were used among people with different profiles.

Results: Individuals with profiles at the extremes of the model (e.g., self-fulfilling vs. self-destructive) differed the most in their use of strategies. The differences within individuals with profiles that diverge in one affectivity dimension while being similar in the other suggested that, for example, decreases in negative affect while positive affect is low (self-destructive vs. low affective) will lead or might be a function of a decrease in usage of both the mental control and the passive leisure strategies.

Conclusion: The self-fulfilling experience, depicted as high positive affect and low negative affect, is a combination of agentic (instrumental goal pursuit, active leisure, direct attempts), communal (social affiliation), and spiritual (religion) strategies. Nevertheless, the affective system showed the characteristics of a complex dynamic adaptive system: the same strategies might lead to different profiles (multi-finality) and different strategies might lead to the same profile (equifinality).
\end{abstract}

Keywords: Affective profiles; Cluster analyses; Happiness-increasing scales; Negative affect; Positive affect; Well-being

"However beautiful the strategy, you should occasionally look at the results" Winston Churchill

\section{Introduction}

In well-being research, positive and negative affectivity, have emerged as fundamental markers of human flourishing [2-6]. According to Watson and colleagues $[7,8]$, positive affect involves the experience of emotions from a pleasant engagement dimension (e.g., enthusiastic, active) to an unpleasant disengagement dimension (e.g., sad, bored). Individuals high in positive affect are characterized by enthusiasm, activity, alertness, hardiness (i.e., control, commitment and challenge), their experience of high levels satisfaction with life, self-security and self-confidence, and their ability to create and keep positive social relations with others [8-11]. That is, a general disposition towards a positive attitude both over time and varying circumstances $[12,13]$ or to be more accurate what Cloninger [14] depicts as an outlook of unity. Negative affect, on the other hand, involves the experience of emotions from an unpleasant engagement dimension (e.g., anger, fear) to a disengagement dimension (e.g. calm, serene) $[8,11]$, thus, reflecting expressions such as anger, disgust, guilt, shame, fear and sadness $[7,15]$. Positive and negative affect are therefore seen as two independent dimensions in which individuals might experience either high and/or low affectivity, thus, leading to the possibility of four different combinations [16].
In this line of thought, Archer, Garcia and colleagues have developed the affective profile model, which comprises four profiles: self-destructive (low positive affect, high negative affect), high affective (high positive affect, high negative affect), low affective (low positive affect, low negative affect), and self-fulfilling (high positive affect, low negative affect) [17-25]. These studies have shown that individuals' levels of energy and optimism are higher among those with a selffulfilling profile than among individuals with any of the other three affective profiles [20]. In addition, also higher levels of life satisfaction, psychological well-being, and agentic values (i.e. autonomy, responsibility, self-acceptance) in combination with lower depressive symptoms are characteristic of individuals with a self-fulfilling profile. There is, indeed, growing evidence that positive affect and life satisfaction are associated with positive outcomes in relationships, work, and

*Corresponding author: Garcia D, Network for Empowerment and Well-Being, Axel W. Anderssons Väg 8A, SE 371 62, Lyckeby, Sweden; Tel: +46 31 7864694; E-mail: danilo.garcia@icloud.com

Received: August 16, 2016; Accepted: August 29, 2016; Published: September 05, 2016

Citation: Garcia D, Schütz E, MacDonald S, Archer T (2016) Differences in Happiness- Increasing Strategies Between and Within Affective Profiles. Clin Exp Psychol 2: 139. doi: 10.4172/2471-2701.1000139

Copyright: @ 2016 Garcia D, et al. This is an open-access article distributed under the terms of the Creative Commons Attribution License, which permits unrestricted use, distribution, and reproduction in any medium, provided the original author and source are credited. 
Citation: Garcia D, Schütz E, MacDonald S, Archer T (2016) Differences in Happiness- Increasing Strategies Between and Within Affective Profiles. Clin Exp Psychol 2: 139. doi: 10.4172/2471-2701.1000139

Page 2 of 7

\begin{tabular}{|c|c|}
\hline Happiness-increasing strategies & Definition \\
\hline Social Affiliation & $\begin{array}{l}\text { Comprises communal values (i.e., cooperation) to guide behavior such as: supporting and encouraging } \\
\text { friends, savoring the moment, receiving help from friends, interacting with friends, and caring for } \\
\text { maintaining social relations. }\end{array}$ \\
\hline Partying and Clubbing & $\begin{array}{l}\text { Includes activity of a celebratory nature such as partying, going out to clubs with friends, going out to } \\
\text { meet people or for entertainment, drinking alcohol, and dancing. }\end{array}$ \\
\hline Mental Control & $\begin{array}{l}\text { This strategy is the individual's tendency to emphasize avoiding negative experiences by suppressing } \\
\text { negative thoughts and feelings but also, at the same time, ponder about negative aspects of life (e.g., } \\
\text { trying not to think about being unhappy, thinking about what is wrong in life, trying to think positively but } \\
\text { failing, focusing out negative aspects of life). }\end{array}$ \\
\hline Instrumental Goal Pursuit & $\begin{array}{l}\text { Includes activities directed to achieving goals by pursuing career goals, trying to reach one's full } \\
\text { potential, striving for the accomplishment of tasks, trying to do well academically, and organizing one's } \\
\text { life and goals. }\end{array}$ \\
\hline Passive Leisure & $\begin{array}{l}\text { Characterized by idleness such as watching TV and playing video games, surfing the internet, going to } \\
\text { the movies with friends, shopping, and sleeping. }\end{array}$ \\
\hline Active Leisure & $\begin{array}{l}\text { Comprises a propensity for wellness through fitness and flow, that is, exercising and working on } \\
\text { hobbies. }\end{array}$ \\
\hline Religion & $\begin{array}{l}\text { Comprises performing religious activities such as praying, performing religious ceremonies and seeking } \\
\text { support from faith. }\end{array}$ \\
\hline Direct Attempts & $\begin{array}{l}\text { Includes explicit behaviors, such as, acting happy and smiling, getting oneself into a good mood, and } \\
\text { deciding to be happy. }\end{array}$ \\
\hline
\end{tabular}

Table 1: Definition of each of the happiness-increasing strategies [30].

physical health (for a review see [26]). Moreover, a self-fulfilling profile, which is at the fundamental level an optimistic disposition or a happy personality [27], has been linked to biological (e.g., better physical health), psychological (e.g., more effective coping strategies), and social (e.g., positive relationships with others) constructs [20,21,28]. In the pursuit of happiness, for instance, people seem to use eight specific strategies to maintain or increase happiness $[29,30]$ : social affiliation, partying and clubbing, instrumental goal pursuit, mental control, active leisure, passive leisure, direct attempts, and religion (see Table 1 for a definition of each strategy). In this context, depending on their affective profile, individuals should differ in which strategies they use to increase their happiness, since individuals with different profiles vary in aspects of cognition, emotion, and conation $[1,20,24,31]$.

Indeed, in a recent study [1], using the affective profile model as the backdrop for the investigation, the major findings were that individuals with a self-destructive profile used seven of the eight happiness-increasing strategies to a significantly lower extent than all other profiles. The only exception was that individuals with a selfdestructive profile were more prone to try to increase their happiness by suppressing negative thoughts and feelings but at the same time, also pondering about negative aspects of life (i.e., mental control strategy). Moreover, individuals with a self-fulfilling profile reported using the mental control strategy less often than individuals with a high negative affect profile (i.e., high affects and self-destructives). In other words, the tendencies that are characteristic of mental control are not only significantly different between unhappy (i.e., who express a self-destructive profile) and happy individuals (i.e., who express a self-fulfilling profile), but also within individuals who experience high levels of positive affect (i.e., high affective vs. self-fulfilling).

This and other findings show that the affective profile model is person-centered (cf. [32,33]) because it allows the comparison of individuals who differ in one affect dimension and are similar in the other-a model of positive and negative affect as a complex dynamic adaptive system within the individual (cf. [34]). Specifically, a common comparison or linear association would only suggest that mental control is positively related to negative affect and negatively to positive affect. In contrast, using the affective profile model as the backdrop of the investigation of individual differences, mental control as a strategy to increase happiness seems to be associated to high levels of negative affect when the individual is low in positive affect (i.e., between differences: self-destructive vs. self-fulfilling), but also when positive affect is high (i.e., between differences: high affective vs. self-fulfilling). That is, increases in positive emotions or experiences would not decrease individuals' tendency to rumination and avoidance of negative experiences by suppressing negative thoughts, as long as they are not accompanied with decreases in negative emotions or experiences (cf. $[35,36])$.

Furthermore, the affective profile model also helped us to understand that individuals with a self-fulfilling profile used strategies related to agency (e.g., instrumental goal pursuit, direct attempts), communion (e.g., social affiliation), and spirituality (e.g., religion) more often [1]. In short, in order to increase their happiness, individuals with a self-fulfilling profile are more prone to directly attempt to smile, get them selves in a happy mood, improve themselves, and work on their self-control (i.e., agency); they tend also to pursue cooperative values, such as, support and encourage friends, help and receive help from others, and try to improve social skills (i.e., communion); as they tend seek support from faith, perform religious activities, pray, and drinking less alcohol (i.e., spirituality). Nevertheless, individuals with either a low affective or high affective profile used different strategies to a higher rate when compared to those with a self-destructive profile. These differences show, again, that the affective profiles model provides information about individuals that are equal in one affective dimension but are different in another. These differences might be useful to understand how one affective dimension is related to specific strategies, while the other affective dimension is held constant.

\section{The Present Study}

In the present study we aim to replicate the Schütz and colleagues' findings [1] using a merged larger sample described in Nima and Garcia's study [37]. Although this sample also comprises the original cohort from Schütz and colleagues [1], we used a two times larger sample (see [38], who suggest the use of larger samples when replicating results). More importantly, the present study differs in two specific methodological issues. Firstly, instead of the most commonly used median split method used by, for example, Schütz and colleagues [1], we used k-means cluster analysis for the profiling. This procedure is useful for person-oriented analyses because it is a bottom-up procedure in which participants are first sequentially grouped by their similarity on variables of interest (e.g., positive affect and negative affect) [39]. 
In contrast, median splits, the method used by Schütz and colleagues [1], might distort the meaning of high and low because individuals' scores just-above and just-below the median become high and low without being truly high or low (for a comparison between these two procedures see [40]). Secondly, instead of using the 53-items version of the happiness-increasing strategies scales used by Schütz and colleagues [1], we used a factor validated 33-items version [37]. Besides these two methodological issues that separates the present study from that of Schütz and colleagues [1], we also focus in discussing our results on matched comparisons or differences between profiles that are similar in one affective dimension and differ in the other. We do this in order to shade some light on what changes could be expected when individuals increase/decrease their experience of positive or negative affect: selfdestructive vs. high affective (matching: high-high negative affect, differing: low-high positive affect), self-destructive vs. low affective (matching: low-low positive affect, differing: high-low negative affect), high affective vs. self-fulfilling (matching: high-high positive affect, differing: high-low negative affect), and low affective vs. self-fulfilling (matching: low-low negative affect, differing: low-high positive affect).

\section{Method}

\section{Participants and procedure}

US-residents $(N=1000$, age mean $=34.22 \mathrm{sd} .=12.73$, 404 males and 596 females; observe that this is the same sample as the one used in Nima and Garcia's study [37]) were recruited through Amazons' Mechanical Turk (MTurk; https://www.mturk.com/mturk/welcome; see [41]) and got paid \$ 0.50 for their involvement in the study. Participants were informed that the study was confidential and voluntary.

\section{Instruments}

Positive affect and negative affect schedule [7]: This instrument consist of 20 items that participants rate to what extent $(1=$ very slightly, $5=$ extremely) they generally have experienced 20 different feelings or emotions (e.g., positive affect: strong, proud, and interested; negative affect: afraid, ashamed and nervous). Cronbach's a were .89 for the positive affect scale and .91 for the negative affect scale in the present study.

Happiness-increasing strategies scales [30]: The 33 items (1 = never, $7=$ all the time) are organized in eight clusters of strategies: social affiliation (e.g., "Support and encourage friends"; Cronbach's $\alpha=.77$ ), partying and clubbing (e.g., "Drink alcohol"; Cronbach's $\alpha=.75$ ), mental control (e.g., "Try not to think about being unhappy"; Cronbach's $\alpha=$ .52), instrumental goal pursuit (e.g. "Attempt to reach full potential"; Cronbach's $\alpha=.75$ ), passive leisure (e.g. "Surf the internet”; Cronbach's $\alpha=.52$ ), active leisure (e.g. "Exercise"; Cronbach's $\alpha=.65$ ), religion (e.g. "Seek support from faith"; Cronbach's $\alpha=0.70$ ), and direct attempts (e.g. "Act happy/smile, etc."; Cronbach's $\alpha=.76$ ).

\section{Statistical treatment and analyses}

Statistical analyses showed that there were no significant differences between the original sample $(N=500)$ and the new cohort $(N=500)$ in any of the studied variables. A Chi-Square (Goodness of fit) indicated that there were no significant gender differences between the samples $\left(\chi^{2}(1, N=1000)=3.738, p>0.05\right)$. Further analysis using t-test showed no significant differences between the samples regarding age, positive and negative affect and happiness-increasing strategies. Subsequent analyses were therefore conducted using both samples as one whole merged sample.

The statistical program Ropstat [42] (http://www.ropstat.com) was used to cluster participants into the four affective profiles. Specifically, hierarchical k-means cluster analyses with Ward's method and Average Squared Euclidian distance measures was used to allocate individuals into four profiles, The correlates of cluster membership were analyzed by means of multinomial regressions using the self-destructive group as the reference group (see $[40,43])$. The four profiles explained a suboptimal variation of $62.8 \%$ : self-fulfilling $(n=380)$, low affective $(n$ $=239)$, high affective $(n=207)$, and self-destructive $(n=172)$.

Analyses of variance (ANOVA), using SPSS version 20, were conducted with the affective profile as the independent variable and with happiness-increasing strategies as the dependent variables. Post hoc tests with Bonferroni correction were performed for data exhibiting homogeneity of variance according to Levene's test. When homogeneity of variance was not met, post hoc tests according to Games-Howell were performed. For these variables, Welch's test of equality of means was used to assess any significant differences between groups.

\section{Results}

The ANOVA indicated a significant effect on the strategies by the individuals' type of affective profile $\left(F_{(24,2931)}=12.79 ; p<0.001, \eta^{2}=\right.$ 0.095 , power $=1.00)$. A One-way ANOVA with affective profiles as the independent variable indicated significant differences upon all the happiness-increasing strategies among the affective profiles: social affiliation $\left(F_{(3,455.864)}=58.22, \mathrm{p}=.000\right.$, est. $\left.\omega^{2}=.147\right)$, partying and clubbing $\left(F_{(3,996)}=22.47, p=.000, \eta^{2}=.063\right.$, power $\left.=1.00\right)$, mental control $\left(F_{(3,996)}=58.91, p=.000, \eta^{2}=.151\right.$, power $\left.=1.00\right)$, instrumental goal pursuit $\left(F_{(3,463.801)}=50.41, p=.000\right.$, est. $\left.\omega^{2}=.129\right)$, Religion $\left(F_{(3,996)}\right.$ $=7.00, p=.000, \eta^{2}=.021$, power $\left.=0.98\right)$, passive leisure $\left(F_{(3,996)}=8.50\right.$, $p=.000, \eta^{2}=.025$, power $\left.=0.994\right)$, active leisure $\left(F_{(3,996)}=43.30, p=\right.$ $.000, \eta^{2}=.115$, power $\left.=1.00\right)$, and direct attempts $\left(F_{(3,456,268)}=91.59, p\right.$ $=.000$, est. $\left.\omega^{2}=.214\right)$.

A Games-Howell test, with alpha level set to 0.01 , was conducted to compare the mean differences in happiness-increasing strategies between individuals with the four affective profiles. The results showed that the individuals with a self-fulfilling profile had among the highest scores in all happiness-increasing strategies except for mental control and passive leisure, in which individuals with a self-destructive profile scored the highest. More specifically, individuals with a self-fulfilling profile reported more frequent use of social affiliation (compared to all profiles), partying and clubbing (compared to individuals with self-destructive and low affective profiles), instrumental goal pursuit (compared to individuals with self-destructive and low affective profiles), active leisure (compared to individuals with self-destructive and low affective profiles), religion (compared to individuals with a low affective profile), and direct attempts (compared to all profiles).

Individuals with a high affective profiles also reported more frequent use of social affiliation (although lower compared to individuals with the self-fulfilling profile), partying and clubbing (compared to individuals with self-destructives and low affective profiles), mental control (compared to individuals with a self-fulfilling profile), instrumental goal pursuit (compared to individuals with self-destructive and low affective profiles), passive leisure (compared to individuals with the low affective profile), active leisure (compared to individuals with selfdestructive and low affective profiles, but lower than individuals with a self-fulfilling profile), and direct attempts (compared to individuals with self-destructive and the low affective profiles, but lower than individuals with a self-fulfilling profile).

The individuals with a low affective profile scored lower than the individuals with a self-fulfilling profile in the strategies of social 
affiliation, partying and clubbing, instrumental goal pursuit, religion, passive leisure active leisure and direct attempts, however not lower than the individuals with a self-destructive profile. The individuals in the self-destructive profile scored higher in mental control (compared to all the profiles) and passive leisure (compared to low affective). For further details, see Table 2 .

\section{Discussion}

The aim of the present study was to replicate the findings from Schütz and colleagues [1] using a larger sample, a person-oriented method to construe the four affective profiles (i.e., cluster analysis), and a recently validated measure of the happiness-increasing strategies scale originally created by Tkach and Lyubomirsky [30]. In essence, the findings by Schütz and colleagues were replicated. Specifically, the results showed that individuals with a self-fulfilling profile used three of the eight happiness-increasing strategies to a larger extent (i.e., social affiliation, active leisure, and direct attempts) than individuals with any of the other profiles. As in the original study [1], this suggests a higher level of cooperative and agentic behavior among individuals with this specific affective profile. The activities in the social affiliation strategy do comprise cooperative values: supporting and encouraging friends, helping others, interacting with friends, and receiving help from friends. The activities in the direct attempts and active leisure strategies do comprise self-directed and agentic choices that enables the individual to have control over their lives and own well-being: directly attempt to smile, get oneself in a happy mood, work on one's self-control, exercise (cf. [44]). Importantly, self-directed and cooperative behavior is related to psychological well-being [45-47], mental health, dysfunction and suffering related to specific disorders [27,48-50]. In addition, selfdirected and cooperative behaviors are suggested to influence biological (e.g., physical health), psychological (e.g., happiness), and social (e.g., harmony) well-being [51] (see also [52], who showed that increases in agency and cooperation are associated to improvement in depression). The differences found here, however, are more congruent across profiles. Past findings, for instance, have not showed higher tendency among individuals with a self-fulfilling profile to use social affiliation and active leisure more frequently than individuals with a high affective profile. We argue that these discrepancies between our results and those in the Schütz and colleagues' study [1] might depend on the different methods used to group individuals in different profiles.

The use of cluster analyses to categorize individuals in different profiles does indeed create profiles that are more heterogeneous between groups and equally homogeneous within groups [40]. Hence, the differences found here might correspond to actual differences between profiles. In this line, the results here showing that individuals with a self-destructive profile use the strategy of mental control more often than individuals with any of the other profiles is probably more straightforward and consistent through comparisons than in the original study [1]. Furthermore, differences in the usage of social affiliation as a happiness-increasing strategy between individuals with a low affective and those with a high affective profiles are also more consistent with related research, such as, the notion of extroversion being related to more frequently socializing when compared to introversion (see Garcia [53], who showed that individuals with a high affective profile report higher levels of extroversion than individuals with a low affective profile). Again, we suggest that we see this consistency and "cleanness" in the results might be due to the person-oriented approach used to create the profiles and to the use of a more reliable and valid measure of the happiness-increasing strategies scales in the present study.

As in the original study [1], the differences in happiness-increasing strategies between individuals found at the extreme from each other are rather similar-at least when the self-fulfilling profile was compared to the self-destructive profile (i.e., high positive and low negative affect vs. low positive and high negative affect). However, when the other extremes were compared, high affective vs. low affective (i.e., high positive and negative affect vs. low positive and negative affect), our results show that this individuals differ in their usage of all strategies except two (i.e., mental control and religion). See Figure 1, black arrows, for differences when profiles at each extreme were compared in the present study. In Schütz and colleagues' study [1], individuals with these profiles differed only in the strategies of mental control and goal pursuit. At first sight, the comparison between extremes suggests that most of the happinessincreasing strategies are associated with high levels of positive affect even when the individual is high in negative affect, which is accordingly to Fredrickson's theory of positive emotions: positive emotions serve as a buffer against negative ones [54].

That being said, we also mapped the differences between profiles that differ in one affectivity dimension while holding the other constant in order to understand in which conditions increases/decreases in any of the affectivity dimensions will lead to changes in usage of strategies (see Figure 1, grey arrows). For example, decreases in negative affect while positive affect is low (self-destructive vs. low affective) will lead or might be a function of a decrease in usage of both the mental control and the passive leisure strategies. In contrast, an increase in positive affect while negative affect is high (self-destructive vs. high affective) will lead or might be a function of both an increase in the usage of five strategies and the decrease in the usage of mental control. Increases in social affiliation were related to increases in positive affect when negative affect was high (self-destructive vs. high affective) or low (low affective vs. self-fulfilling), but also to low levels of negative affect when positive affect was high (high affective vs. self-fulfilling). This is in line

\begin{tabular}{|c|c|c|c|c|}
\hline & Self-destructive $(n=172)$ Mean (SE) & Low affective $(n=239)$ Mean $(S E)$ & $\begin{array}{c}\text { High affective }(n=207) \text { Mean } \\
\text { (SE) }\end{array}$ & $\begin{array}{l}\text { Self-fulfilling }(n=380) \text { Mean } \\
\text { (SE) }\end{array}$ \\
\hline Social Affiliation* & $3.21(.06)$ & $3.42(.05)$ & $3.74^{\mathrm{D}, \mathrm{L}}(.0 .4)$ & $3.98^{\mathrm{D}, \mathrm{L}, \mathrm{H}}(.03)$ \\
\hline Partying and Clubbing & $2.33(.04)$ & $2.39(.03)$ & $2.68^{\mathrm{D}, \mathrm{L}}(.04)$ & $2.65^{\mathrm{D}, \mathrm{L}}(.03)$ \\
\hline Mental Control & $3.30^{L, H, F}(.05)$ & $2.65(.05)$ & $2.80^{F}(.05)$ & $2.45(.04)$ \\
\hline $\begin{array}{c}\text { Instrumental Goal } \\
\text { Pursuit }^{*}\end{array}$ & $3.12(.07)$ & $2.97(.06)$ & $3.56^{\mathrm{D}, \mathrm{L}}(.05)$ & $3.74^{\mathrm{D}, \mathrm{L}}(.04)$ \\
\hline Religion & $2.26(.07)$ & $2.19(.06)$ & $2.41(.07)$ & $2.54^{\llcorner}(.05)$ \\
\hline Passive Leisure & $3.42^{\mathrm{L}}(.04)$ & $3.17(.04)$ & $3.40^{\llcorner}(.04)$ & $3.30(.03)$ \\
\hline Active Leisure & $2.94(.07)$ & $3.15(.06)$ & $3.48^{\mathrm{D}, \mathrm{L}}(.06)$ & $3.73^{\mathrm{D}, \mathrm{L}, \mathrm{H}}(.04)$ \\
\hline Direct Attempts* & $2.95(.07)$ & $3.08(.06)$ & $3.56^{\mathrm{D}, \mathrm{L}}(.05)$ & $3.99^{\mathrm{D}, \mathrm{L}, \mathrm{H}}(.04)$ \\
\hline
\end{tabular}

Table 2: Mean differences between individuals with the four affective profiles. All significant differences are at the $p<0.01$ level. Note: SE $=$ standard error; ${ }^{*}$ Homogeneity of variance according to Levene's test was not met. Welch test of equality of means revealed a significant difference between groups; ${ }^{\mathrm{D}}$ significantly higher compared to individuals with a self-destructive profile, ${ }^{\mathrm{L}}$ significantly higher compared to individuals with a low affective profile; ${ }^{\mathrm{H}}$ significantly higher compared to individuals with a high affective profile; ${ }^{F}$ significantly higher compared to individuals with a self-fulfilling profile. 
Citation: Garcia D, Schütz E, MacDonald S, Archer T (2016) Differences in Happiness- Increasing Strategies Between and Within Affective Profiles. Clin Exp Psychol 2: 139. doi: 10.4172/2471-2701.1000139

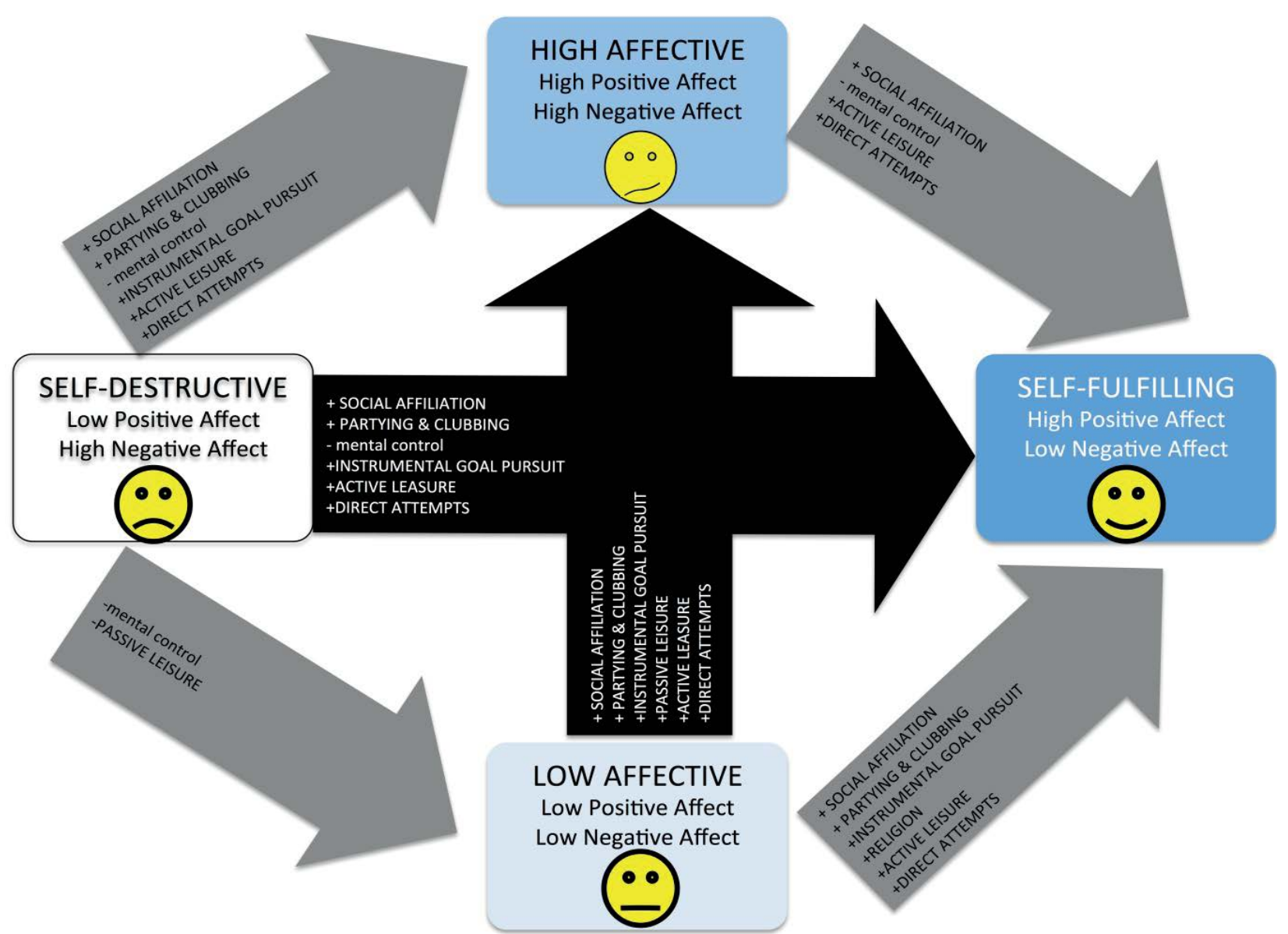

Figure 1: (Black arrows) Differences found between individuals with affective profiles that are at their extremes: self-destructive vs. self-fulfilling (low-high positive affect, high-low negative affect) and low affective vs. high affective (low-high positive affect, low-high negative affect). (Grey arrows) Differences found when individuals were matched in one affective dimension, and differed in the other (i.e., within differences): self-destructive vs. high affective (matching: highhigh negative affect, differing: low-high positive affect), self-destructive vs. low affective (matching: low-low positive affect, differing: high-low negative affect), high affective vs. self-fulfilling (matching: high-high positive affect, differing: high-low negative affect), and low affective vs. self-fulfilling (matching: low-low negative affect, differing: low-high positive affect). Note: Reprinted with permission from Well-Being and Human Performance Sweden AB.

with studies that suggest that certain behaviors, such as the ability to create and keep strong and meaningful social relations, are associated to well-being across many situations [55]. In this line, we could discern or simulate many changes from one profile to another when individuals increase or decrease the usage of any of the eight happiness-increasing strategies (see Figure 1). In sum, the affective system shows the characteristics of complex adaptive systems: the same antecedents lead to different outcomes (i.e., multi-finality) and different antecedents lead to the same outcome (i.e., equifinality) (cf. [48]).

\section{Limitations and Suggestions for Future Research}

The cross-sectional design of the present study only permitted us to suggest theoretical "changes" from one profile to another. Importantly, individuals were allocated in profiles using a person-centered method or a bottom-up procedure that sequentially groups individuals by their similarity on positive affect and negative affect (i.e., pattern and individual focused) $[40,43,56]$. In this respect cluster analytic methods are data-driven and create affective profiles groups that are relative to each other. Data driven methods, compared to median-splits, come closer to modeling the dynamic nature of within and between group variability of individual patterns of affectivity, while the median-split procedure is static in nature-equally sized groups are pre-determined because two variables are each divided in high and low using the median [40]. Thus, the results of matched comparisons discussed here are plausible to be found when longitudinal data is used to scrutinize possible changes in an individual who moves from one profile to another. In other words, since these comparisons help to discern differences between individuals in one affectivity dimension, while holding the other constant (cf. [48]), we suggest that these are plausible movements or leaps that individuals could be expected to make when their affectivity system changes or when new behavior is learned (i.e., the integration of one happinessincreasing strategy as part of one's life style). In this case, we suggest that the movement of an individual is more likely to be as depicted in Figure 1's grey arrows, rather than Figure 1's black arrows. This can be investigated using person-centered methods, such as, cell-wise analysis in which a reference (i.e., an estimated expected cell frequency) to which the observed cell frequency is compared see $[57,58]$.

Moreover, the use of MTurk might influence the validity of the results. Plausible points of caveats are workers' attention levels, cross-talk between participants, and the fact that participants get remuneration for their answers [41]. Nevertheless, a large quantity of studies show that data on psychological measures collected through MTurk meets academic standards (e.g., $[41,59,60,61])$. One final limitation worth mentioning is 
Citation: Garcia D, Schütz E, MacDonald S, Archer T (2016) Differences in Happiness- Increasing Strategies Between and Within Affective Profiles. Clin Exp Psychol 2: 139. doi: 10.4172/2471-2701.1000139

Page 6 of 7

that although we used a validated measure for the assessment of happinessincreasing strategies, the alphas of some of the clusters of strategies were rather low (see also [37]). A way to improve the instrument is to re-organize the items around a stronger theoretical biopsychosocial basis rather than the factor analyses organization proposed by Tkacth and Lyubomirsky [30]. In this context, Cloninger [14] has suggested that human thought can be organized across five planes based on the heriercharly development of the brain through evolution. Each of the planes matches a specific modulation of a different basic emotional conflict: sexual, material, emotional, intellectual, and spiritual. As Nima and Garcia [37], we suggest that Cloninger's five planes can be useful in a re-organization of the strategies and in the addition of new important strategies. As matter of fact, the measure lacks items corresponding to basic needs, such as those corresponding to the sexual plane, and self-actualizing needs, such as those corresponding to the spiritual plane.

\section{Conclusion and Final Remarks}

The affective system shows the characteristics of a complex dynamic adaptive system: the same strategies might lead to different profiles (multi-finality) and different strategies might lead to the same profile (equifinality). Nevertheless, the self-fulfilling experience is a combination of agentic (instrumental goal pursuit, active leisure, direct attempts), communal (social affiliation), and spiritual (religion) strategies. That is, high levels of positive affect in combination with low levels of negative affect are a function of exercising intentionality and self-awareness to work on one's self-control, try to improve one self, be in the service of others (e.g., help others and improve social skills), and also having faith.

"Happiness is when what you think, what you say, and what you do are in harmony."

\section{Mahatma Gandhi}

\section{Competing Interests}

Dr. Danilo Garcia is the Director of the Blekinge Center of Competence, which is the Blekinge County Council's research and development unit. The Center works on innovations in public health and practice through interdisciplinary scientific research, person-centered methods, community projects, and the dissemination of knowledge in order to increase the quality of life of the habitants of the county of Blekinge, Sweden. He is also an Associate Professor at the University of Gothenburg and together with Professor Trevor Archer and Associate Professor Max Rapp Ricciardi, the leading researcher of the Network for Empowerment and Well-Being. Dr. Erica Schütz and Dr. Shane MacDonald are both members and researchers at the Network for Empowerment and Well-Being.

\section{Author Contributions}

Danilo Garcia conceived and designed the experiments, performed the experiments, analyzed the data, wrote the paper, prepared figures and/or tables, and reviewed drafts of the paper. Erica Schütz analyzed the data, prepared the tables, and reviewed drafts of the paper. Trevor Archer and Shane MacDonald wrote the paper and reviewed drafts of the paper.

\section{Funding}

The development of this article was funded by AFA Insurance (Dnr 130345). The funders had no role in study design, data collection and analysis, decision to publish, or preparation of the manuscript.

\section{References}

1. Schütz E, Sailer U, Nima AA, Rosenberg P, Andersson Arntén AC, et al. (2013) The affective profiles in the USA: happiness, depression, life satisfaction, and happiness-increasing strategies. PeerJ 1:156.

2. Almagor M, Ben-Porath YS (1989) The Two-Factor Model of Self-Reported Mood: A Cross-cultural Replication. J Pers Assess 53: 10-21.

3. Diener E (1984) Subjective well-being. Psychological Bulletin 95: 542-575.

4. Watson D, Tellegen A (1985) Toward a consensual structure of mood.

\section{Psychological Bulletin 98: 219-235}

5. Zevon MA, Tellegen A (1982) The structure of mood change: An idiographic/ nomothetic analysis. Journal of Personality and Social Psychology 43: 111-122.

6. Cloninger R, Garcia D (2015) The Heritability and Development of Positive Affect and Emotionality.

7. Watson D, Clark LA, Carey G (1988) Positive and negative affectivity and their relation to anxiety and depressive disorders. J Abnorm Psychol 97: 346-353.

8. Watson D, Clark LA (1994) The PANAS-X, Manual for the Positive and Negative Affect Schedule - Expanded form. The University of lowa reports copyright pp. $1-24$.

9. Costa PTJ, McCrae RR (1980) Influence of extroversion and neuroticism on subjective well-being: Happy and unhappy people. Journal of Personality and Social Psychology 38: 668-687.

10. Varg N (1997) Negativ affektivitets inverkan på svarsbeteende i enkätformulär [The influence of negative affect upon responses to questionnaires]. Stockholm: Stockholm University Reports.

11. Watson D, Clark LA (1984) Negative affectivity: The disposition to experience aversive emotional states. Psychological Bulletin 96: 465-490.

12. McCrae RR, Costa PT (1987) Validation of the five-factor model of personality across instruments and observers. Journal of Personality and Social Psychology 1: 81-90.

13. Watson D, Pennebaker JW, Folger R (1986) Beyond negative affectivity Measuring stress and satisfaction in the workplace. Journal of Organizational Behavior Management 8: 141-157.

14. Cloninger CR (2004) Feeling good: The science of well-being. New York: Oxford University Press.

15. Spector PE, O'Connell BJ (1994) The contribution of personality traits, negative affectivity, locus of control and Type A to the subsequent reports of job stressors and job strains. Journal of Occupational and Organisational Psychology 67: $1-11$.

16. Garcia D (2011) Adolescents' happiness: The role of the affective temperament model on memory and apprehension of events, subjective well-being, and psychological well-being. Ph.D. Thesis, University of Gothenburg, Gothenburg.

17. Norlander T, Bood SA, Archer T (2002) Performance during stress: Affective personality, age and regularity of physical exercise. Social Behavior and Personality 30: 495-508.

18. Bood SA, Archer T, Norlander T (2004) Affective personality in relation to general personality, self-reported stress, coping and optimism. Individual Differences Research 2: 26-37.

19. Norlander T, Johansson A, Bood SA (2005) The affective personality: its relation to quality of sleep, wellbeing and stress. Social Behavior and Personality 33 : 709-722.

20. Archer T, Adrianson L, Plancak A, Karlsson E (2007) Influence of affective personality on cognitive-mediated emotional processing: Need for empowerment. European Journal of Psychiatry 21: 248-262.

21. Karlsson E, Archer T (2007) Relationship between personality characteristics and affect: gender and affective personality. Individual Differences Research 5: 44-58.

22. Palomo T, Kostrzewa RM, Beninger RJ, Archer T (2007) Treatment consideration and manifest complexity in comorbid neuropsychiatric disorders. Neurotox Res 12: 43-60.

23. Palomo T, Beninger RJ, Kostrzewa RM, Archer T (2008) Focusing on symtoms rather than diagnoses in brain dysfunction: Conscious and nonconscious expression in impulsiveness and decision making. Neurotox Res 14: 1-20.

24. Archer T, Adolfsson B, Karlsson E (2008) Affective personality as cognitiveemotional presymptom profiles regulatory for self-reported health predispositions. Neurotoxicity Research 14: 21-44.

25. Garcia D, Kerekes N, Andersson-Arntén AC, Archer T (2012) Temperament Character, and Adolescents' Depressive Symptoms: Focusing on Affect. Depress Res Treat.

26. Lyubomirsky S, King L, Diener E (2005) The benefits of frequent positive affect Does happiness lead to success?. Psychol Bull 6: 803-855.

27. Garcia D, Ghiabi B, Moradi S, Siddiqui A, Archer T (2013) The Happy 
Citation: Garcia D, Schütz E, MacDonald S, Archer T (2016) Differences in Happiness- Increasing Strategies Between and Within Affective Profiles. Clin Exp Psychol 2: 139. doi: 10.4172/2471-2701.1000139

Personality: A Tale of Two Philosophies

28. Adrianson L, Ancok D, Ramdhani N, Archer T (2013) Cultural influences upon health, affect, self-esteem and impulsiveness: An Indonesian-Swedish comparison. International Journal of Research Studies in Psychology 2: 25-44.

29. Boehm JK, Lyubomirsky S, Sheldon KM (2011) A longitudinal experimental study comparing the effectiveness of happiness-enhancing strategies in AngloAmericans and Asian Americans. Cogn Emot 25: 1263-1272.

30. Tkach C, Lyubomirsky S (2006) How do people pursue happiness? Relating personality, happiness-increasing strategies, and well-being. Journal of Happiness Studies 7: 183-225.

31. Garcia D, Nima A, Kjell ONE (2014) The affective profiles, psychological wellbeing, and harmony: environmental mastery and self-acceptance predict the sense of a harmonious life. PeerJ 2: e259.

32. Bergman LR, Magnusson D (1997) A person-oriented approach in research on developmental psychopathology. Development and Psychopathology 9: 291319 .

33. Lundh LG (2015) The Person as a Focus for Research - The Contributions of Windelband, Stern, Allport, Lamiell, and Magnusson. Journal of PersonOriented Research 1: 15-33.

34. Cloninger R, Svrakic NM, Svrakic DM (1997) Role of personality selforganization in development of mental order and disorder. Development and Psychopathology 9: 881-906.

35. Needles DJ, Abramson LY (1990) Positive life events, attributional style, and hopefulness: Testing a model of recovery from depression. J Abnorm Psychol 99: 156-165

36. Garcia D, Siddiqui A (2009) Adolescents' affective temperaments: Life satisfaction, interpretation and memory of events. The journal of Positive Psycholgy 4: 155-167.

37. Nima AA, Garcia D (2015) Factor Structure of the Happiness-Increasing Strategies Scales (H-ISS): Activities and Coping Strategies in Relation to Positive and Negative Affect. PeerJ 3: e1059.

38. Lucas RE, Donnellan MB (2013) Improving the replicability and reproducibility of research published in the Journal of Research in Personality. Journal of Research in Personality 4: 453-454.

39. Bergman LR, Magnusson D, El-Khouri BM (2003) Studying individual development in an interindividual context: A person-oriented approach. Mahwah, NJ: Lawrence Erlbaum.

40. Garcia D, MacDonald S, Archer T (2015) Two Different Approaches to The Affective Profiles Model: Median Splits (Variable-Oriented) and Cluster Analysis (Person-Oriented). PeerJ 3: e1380.

41. Buhrmester M, Kwang T, Gosling SD (2011) Amazon's Mechanical Turk: A New Source of Inexpensive, Yet High-Quality, Data?. Perspectives on Psychological Science.

42. Vargha A, Torma B, Bergman LR (2015) ROPstat: A general statistical package useful for conducting person-oriented analyses. Journal of Person-Oriented Research 1: 87-97.
43. MacDonald S, Kormi-Nouri R (2013) The affective personality, sleep, and autobiographical memories. The Journal of Positive Psychology 8: 305-313.

44. Wong KM, Cloninger CR (2010) A Person-Centered Approach to Clinical Practice. Focus 8: 199-215.

45. Helgeson VS (1994) Relation of agency and communion to well-being: Evidence and potential explanations. Psychological Bulletin 116: 412-428.

46. Urry HL, Nitschke JB, Dolski I, Jackson DC, Dalton KM, et al. (2004) Making life worth living: Neural correlates of well-being. Psychol Sci 15: 367-372.

47. Ryff CD (1989) Happiness is everything, or is it? Explorations on the meaning of psychological well-being. Journal of Personality and Social Psychology 57: 1069-1081.

48. Cloninger CR, Zohar AH (2011) Personality and the perception of health and happiness. J Affect Disord 128: 24-32.

49. Garcia D, Anckarsäter H, Lundström S (2013a) Self-Directedness and Cooperativeness, Psychosocial Dysfunction and Suffering in ESSENCE. ScientificWorldJournal.

50. Garcia D, Nima AA, Archer T (2013c) International note: Temperament and character's relationship to subjective well-being in Salvadorian adolescents and young adults. J Adolesc 36: 1115-1119.

51. Cloninger CR (2013) What makes people healthy, happy, and fulfilled in the face of current world challenges?. Mens Sana Monogr 11: 16-24.

52. Johansson R, Lyssarides C, Andersson G, Rousseau A (2013) Personality change after internerdelivered cognitive behavior therapy for depression. PeerJ 1: e39.

53. Garcia D (2012) The Affective Temperaments: Differences between Adolescents in the Big Five Model and Cloninger's Psychobiological Model of Personality. Journal of Happiness Studies 13: 999- 1017.

54. Fredrickson BL (2006) The broaden-and-build theory of positive emotions.

55. Garcia D, Rosenberg $P$ (in press) Out of Flatland: The Role of the Notion of a Worldview in the Science of Well-Being. Men Sana Monographs.

56. Kormi-Nouri R, MacDonald S, Farahani MN, Trost K, Shokri O (2015) Academic Stress as A Health Measure and Its Relationship to Patterns of Emotion in Collectivist and Individualist Cultures: Similarities and Differences. International Journal of Higher Education 4: 92-104.

57. von Eye A, Bogat GA (2006) Person-oriented and variable-oriented research Concepts, results, and development. Merrill-Palmer Quarterly 52: 390-420.

58. von Eye A, Bogat GA, Rhodes JE (2006) Variable-oriented and person-oriented perspectives of analysis: The example of alcohol consumption in adolescence. J Adolesc 29: 981-1004.

59. Horton JJ, Rand DG, Zeckhauser RJ (2011) The online laboratory: conducting experiments in a real labor market. Exp Econ 4: 399-425.

60. Paolacci G, Chandler J, Ipeirotis PG (2010) Running experiments on Amazon Mechanical Turk. Judgment and Decision Making 5: 411-419.

61. Shapiro DN, Chandler J, Mueller PA (2013) Using mechanical turk to study clinical populations. Clinical Psychological Science 1: 213-220. 